278 Darst. v. kohlensäurefr. Aetzkalk. - Reinigungsmeth. d. roh. Antimonmet.

\title{
Darstellung von kohlensilurefreiem Aetzkalk.
}

Der Kalk, wie er im gewöhnlichen Leben gebraucht wird, ist schwerlich jemals völlig kaustisch. Auch bei dem sorgfältigsten Ausglühen in Kleinen wollte es nicht gelingen, die Kohlensäure völli g auszutreiben; der gebrannte Kalk brauste stets merklich mit Säuren auf. Die Umwandelung in reinen, kaustischen Kalk gelingt jedoch leicht und mit Sicherheit, wenn man den einmal geglühten Kalk mit Oel tränkt und ein zweites Mal gliuht. Oel ist vor andern organischen Stoffen geeignet, weil es bequem mit dem Kalk zu mischen, reich an Kohlenstoff ist und keine Asche hinterlässt. Auf diese Weise bei mässiger Rothgluth im Tiegel mit Holzkohle gebrannter Kalk unterscheidet sich von dem gewöhnlichen schon sehr bestimmt durch die Art, wie er sich löscht. Gewöhnlicher Kalk reagirt anfangs gar nicht gegen das Wasser; er liegt eine Zeit lang, auch der fetteste Kalk, oft mehre Minuten eingetaucht, ehe Wärmeentwickelung und Aufquellen beginnt. Lässt man dagegen ein Stück nach obiger Weise gebrannten (reinen) Kalk ins Wasser fallen, so löscht es sich augenblicklich unter hellom $Z$ ischen, wie es eine glühende Kohle hervorbringt. (A. a. O.).

Hog.

\section{Reinigungsmethoden des rohen Antimonmetalls.}

Die Chemical News bringen nachstehende Zusammenstellung der bewährten Reinigungsmethoden des rohen Antimonmetalls. Der rohe Antimonregulus enthält bekanntlich Kupfer, Arsen, Blei, Eisen und Schwefel. Um denselben zu reinigen, schmilzt man ihn mit oxydirenden Zuschlägen (Salpeter oder antimonsaurem Antimonoxyd) und reinigenden Flüssen (Pottasche und Soda) zusammen, damit dic fremden Metalle oxydirt und verschlackt werden; oder man verwandelt letztere durch Zusatz von (Antimonium crudum), Schwefelantimon oder Glaubersalz in Schwefelmetalle, welche in die Schlacke gehen. Durch einen Zuschlag von Kochsalz werden diese Metalle in Chloride verwandelt und verflïchtigen sich entweder als solche, oder sie werden verschlackt. Schwefelantimon wird durch antimonsaures Antimonoxyd in nachstehender Weise zersetzt:

$$
3\left(\mathrm{SbO}^{3}, \mathrm{SbO}^{5}\right)+4 \mathrm{SbS}^{3}=10 \mathrm{Sb}+12 \mathrm{SO}^{2} .
$$

Kohlensaures Natron zersetzt, als Fluss angewendet, das Schwefelarsen unter Entstehung von Kohlensäure, arseniger Säure und Schwefelnatrium. Das letztere verbindet sich mit 
dem Einfach-Schwefeleisen (FeS), dem Arsensulfid (AsS ${ }^{3}$ ) und dem Halbschwefelkupfer ( $\mathrm{Cu}^{2} \mathrm{~S}$ ), während die arsenige Säure an das Natron tritt. Zur vollständigen Entfernung des Arsens ist ein wiederholtes Umschmelzen mit Soda erforderlich; durch einen geringen Eisengehalt wird dieselbe erleichtert, indem sich eine dem Arsenikkies ähnliche Verbindung bildet. Enthält das zu reinigende rohe Antimonmetall kein Eisen, so muss man Schwefeleisen zusetzen.

Ausser diesen sind noch zahlreiche andere Methoden zum Reinigen des rohen Antimonregulus empfohlen worden. So erhitzt z. B. Wöh ler das Metall mit 11/4 Th. seines Gewichts Natronsalpeter und $1 / 2$ Th. kohlensaurem Natron bis zum schwachen Glühen und laugt die Masse mit Wasser aus, wobei arsensaures Natron in Lösung geht; dann schmilzt er den aus $\mathrm{NaO}, \mathrm{SbO}^{5}$ bestehenden Rückstand nach dem Trocknen mit der halben Gewichtsmenge gereinigten und gepulverten Weinstein zusammen und erhält auf diese Weise einen arsenfreien Regulus. Meyer empfiehlt das rohe Metall mit 1/4 Th. Natronsalpeter und $1 / 2$ Th. Soda zu erhitzen, die Masse auszulaugen und den ausgewaschenen und getrockneten Rückstand durcb Zusammenschmelzen mit Weinstein zu reduciren.

Nach Berzelius schmilzt man 2 Th. des Metalls mit $1 \mathrm{Th}$. antimonsaurem Antimonoxyd zusammen. Muspratt empfiehlt das Zusammenschmelzen von $4 \mathrm{Th}$. Antimon mit 1 Th. Braunstein und wiederholtes Umschmelzen des erhaltenen Regulus mit 1/10 seines Gewichts Pottasche. Einen völlig arsenfreien Regulus erhält man nach Bensch auf folgendem Wege: Man schmilat 16 Th. rohes Metall mit 1 Th. Schwefelantimon und 2 Th. trocknem, kohlensauren Natron eine Stunde lang in einem Thontiegel, schlackt nach dem Erkalten den Regulus ab, schmilat diesen nochmals mit 11/2 Th. trocknem, kohlensauren Natron eine Stunde lang und wiederholt dieses Umschmelzen mit $1 \mathrm{Th}$. desselben Flusses noch zum dritten Male. Soll dieses Verfahren seinen Zweck erreichen, so muss das zu reinigende Metall stark eisenhaltig sein. - Chlormagnesium, so wie es aus dem Carnallit, dem Kainit und dem Tachhydrit erhalten werden kann, giebt, in kleinen Mengen dem schmelzenden Antimonregulus zugesetzt, flüchtiges Chlorarsen. Nach $R$. W a g n er liesse sich vielleicht hierauf eine Reinigungsmethode des Antimons gründen. (A. a. O.).

Hbg. 